\title{
FOGLIA E PAESAGGIO DEL CERVELLO
}

Giuseppe Penone 


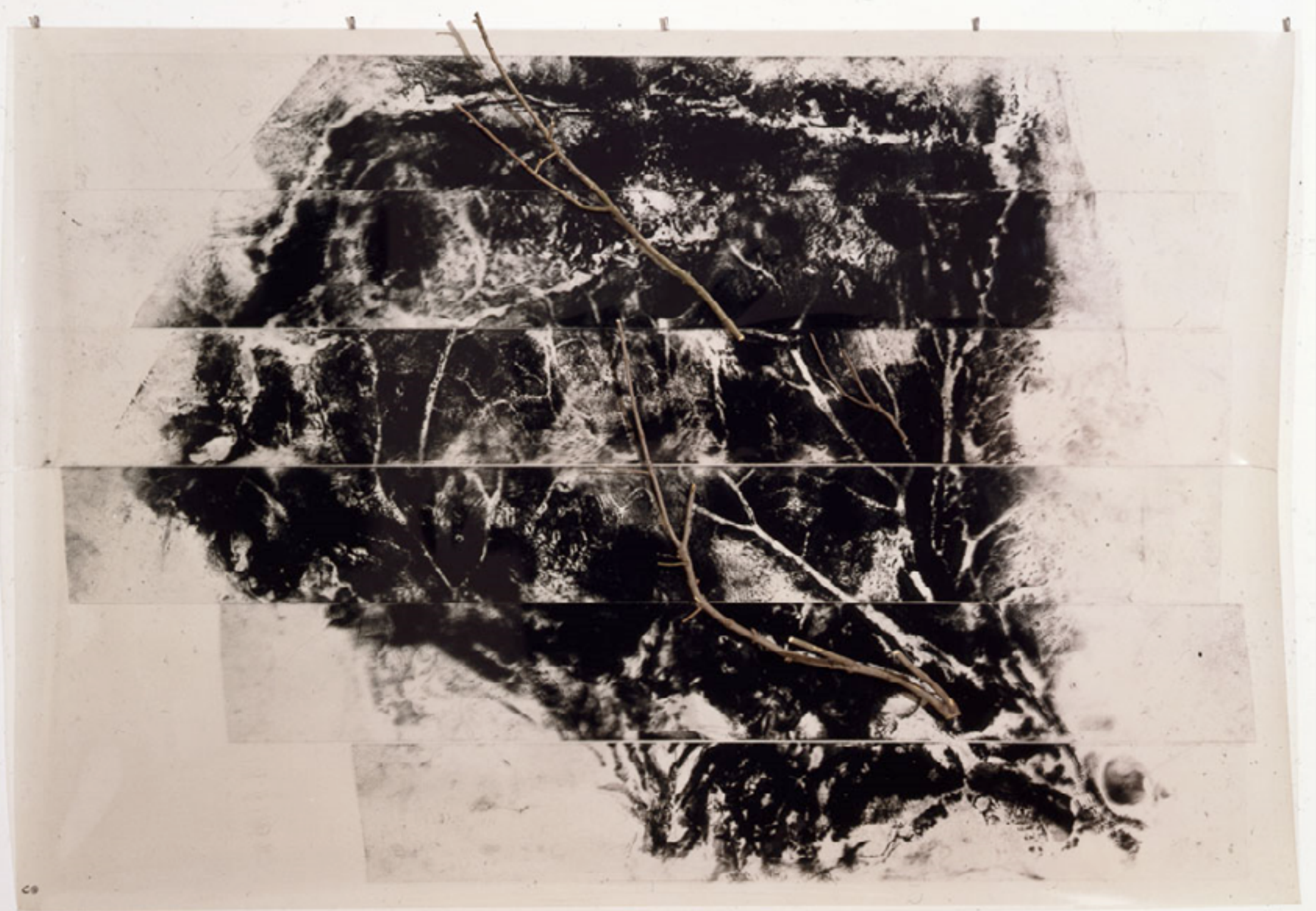

Paesaggio del cervello, 1990 Ampliação fotográfica sobre acetato Marian Goodman Gallery Foto (Michael Goodman 


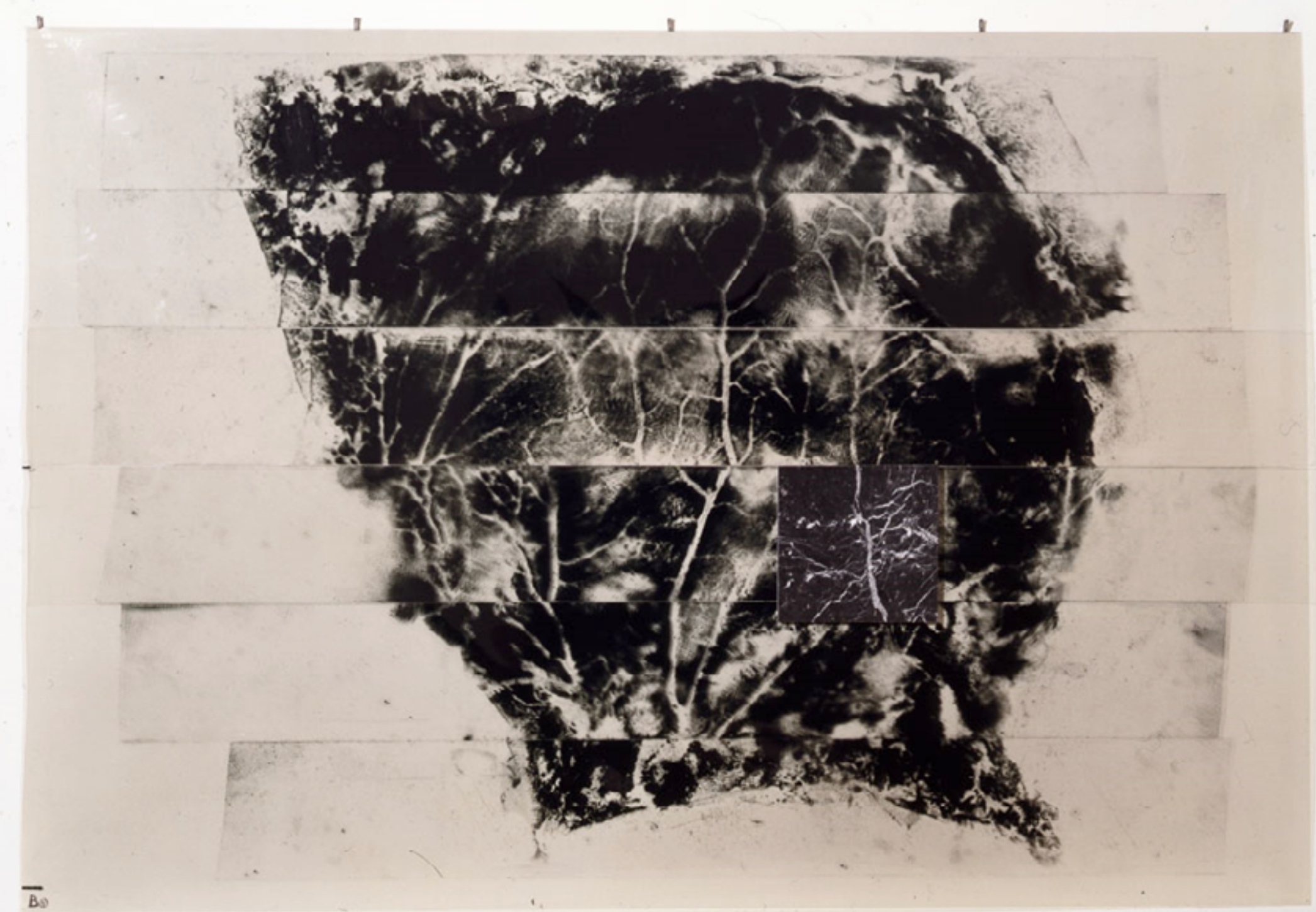

Paesaggio del cervello, 1990 Ampliação fotográfica sobre acetato Marian Goodman Gallery Foto CMichael Goodman 


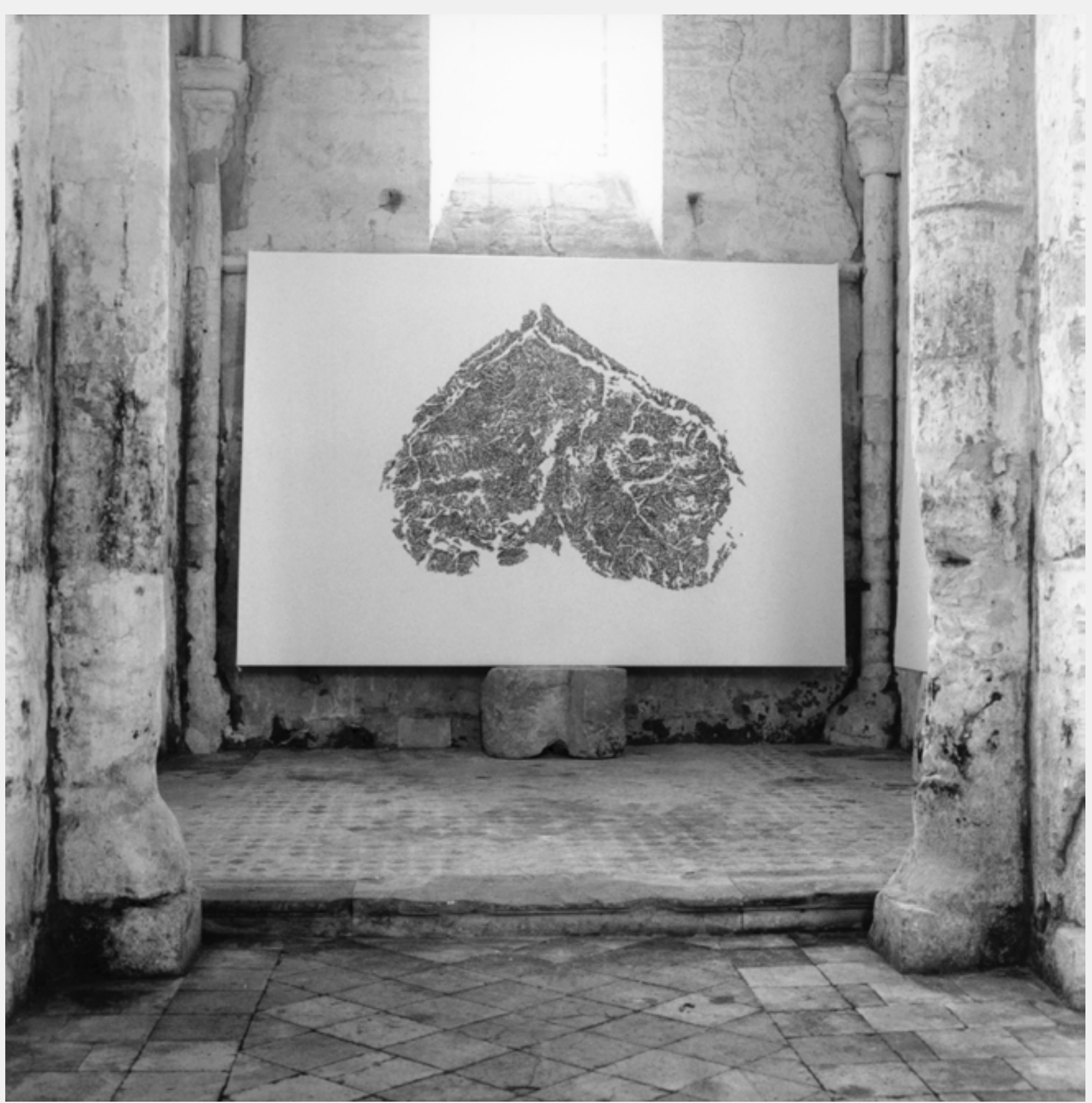

Foglia, 1990

Terra de Siena sobre TNT

$200 \times 300 \mathrm{~cm}$

Coleção Musée de Grenoble (FR)

Foto $\odot$ Musée de Grenoble 


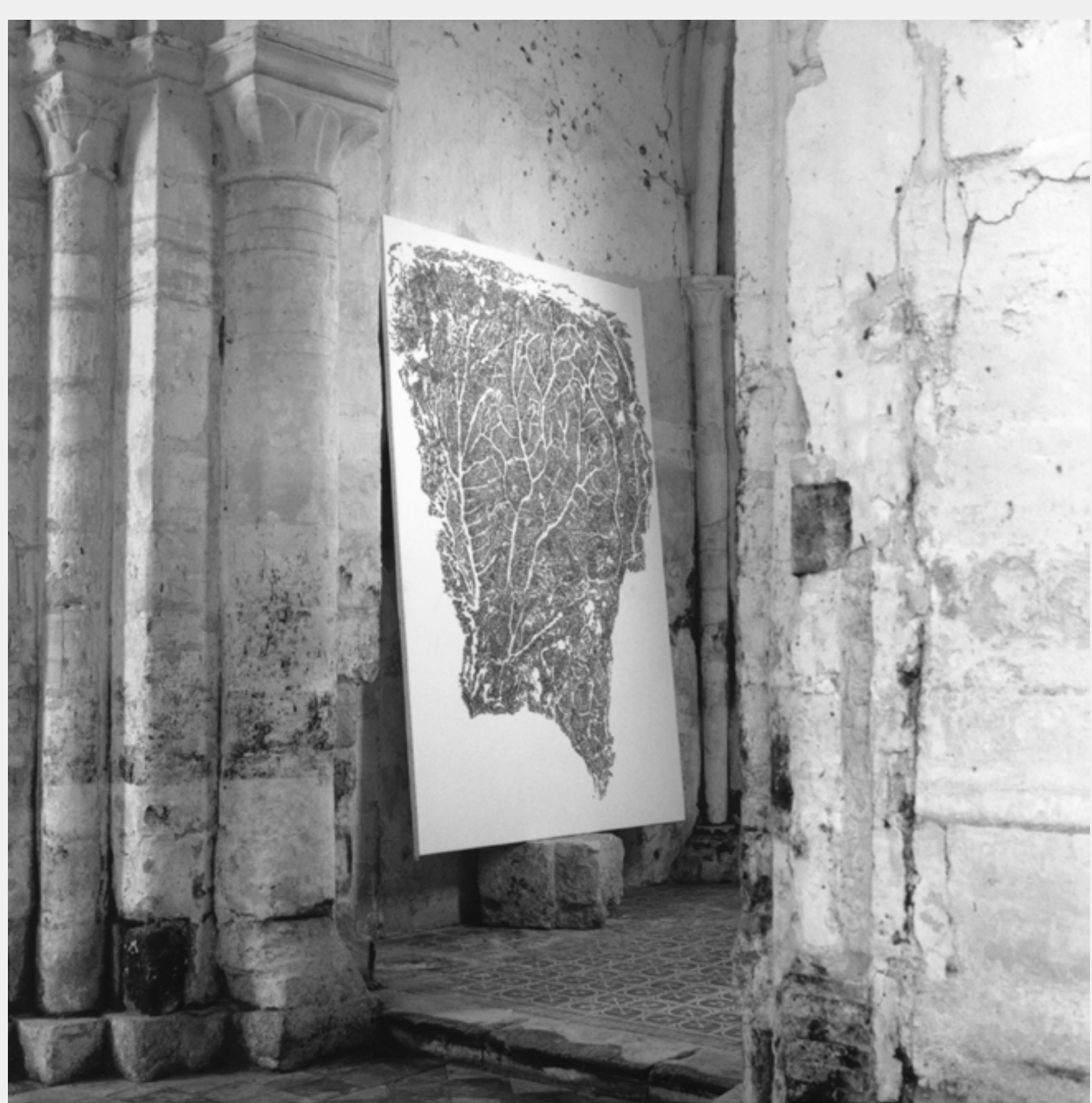

EM TESE
Foglia, 1990

Terra de Siena sobre TNT

$300 \times 200 \mathrm{~cm}$

Coleção Musée de Grenoble (FR)

Foto $\odot$ Musée de Grenoble 


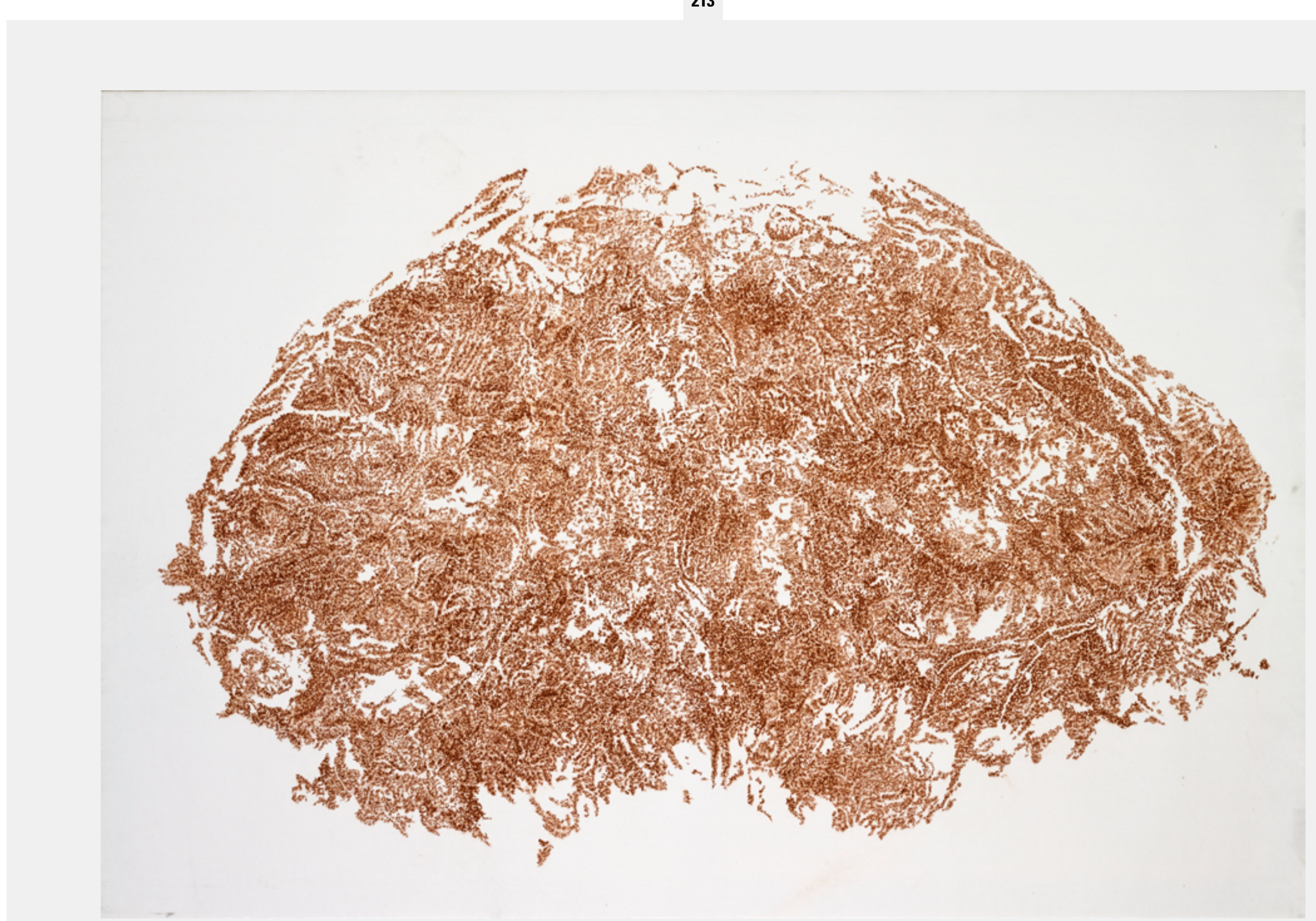

Foglia, 1990 $200 \times 300 \mathrm{~cm}$

Coleção Musée de Grenoble (FR) Foto $\odot$ Gérard Rondeau 


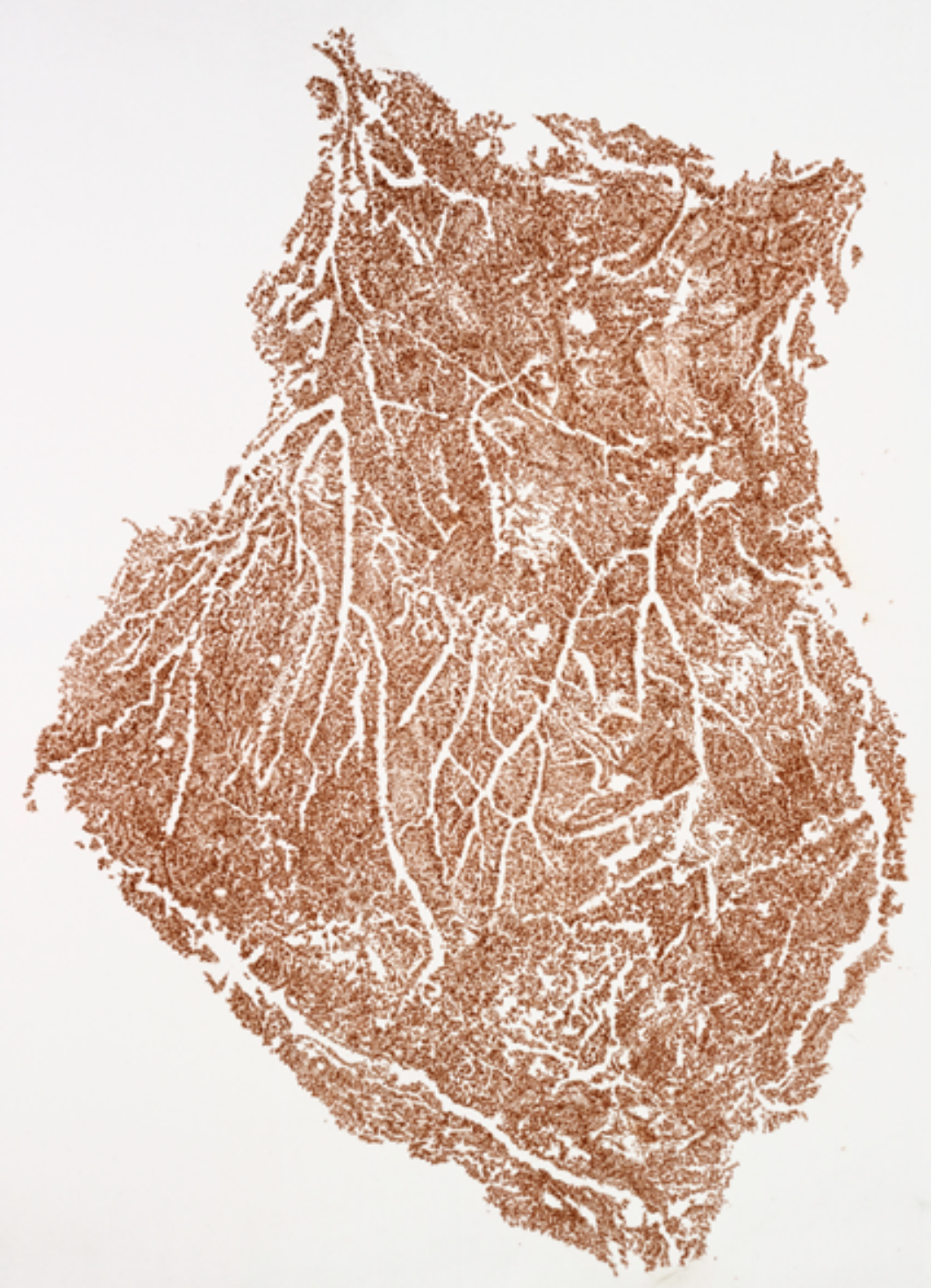

Foglia, 1990

Terra de Siena sobre TNT

$300 \times 200 \mathrm{~cm}$

Coleção Musée de Grenoble (FR)

Foto (c) Gérard Rondeau 


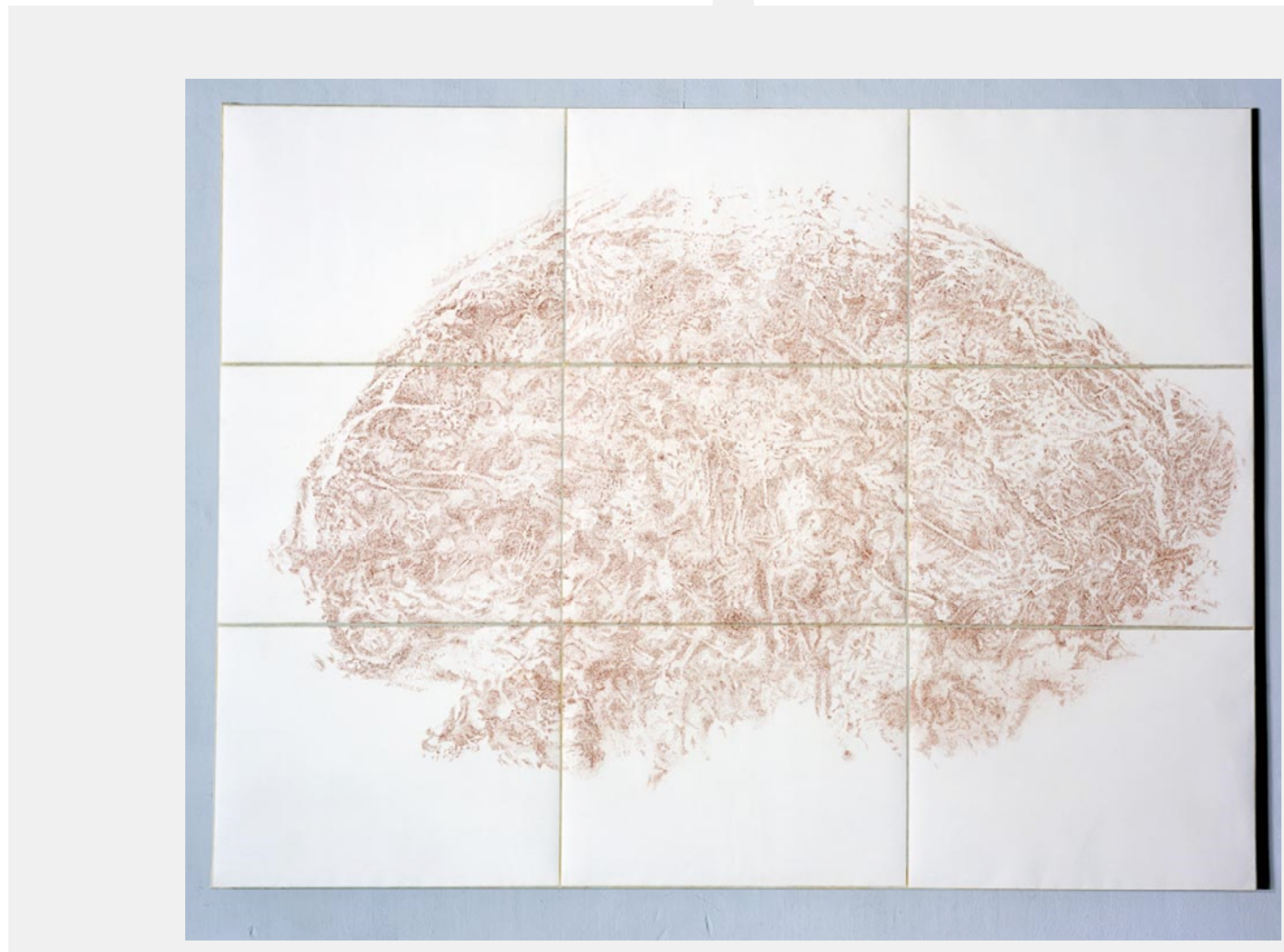

Paesaggio del cervello, 1997 Foto () Arquivo Penone 


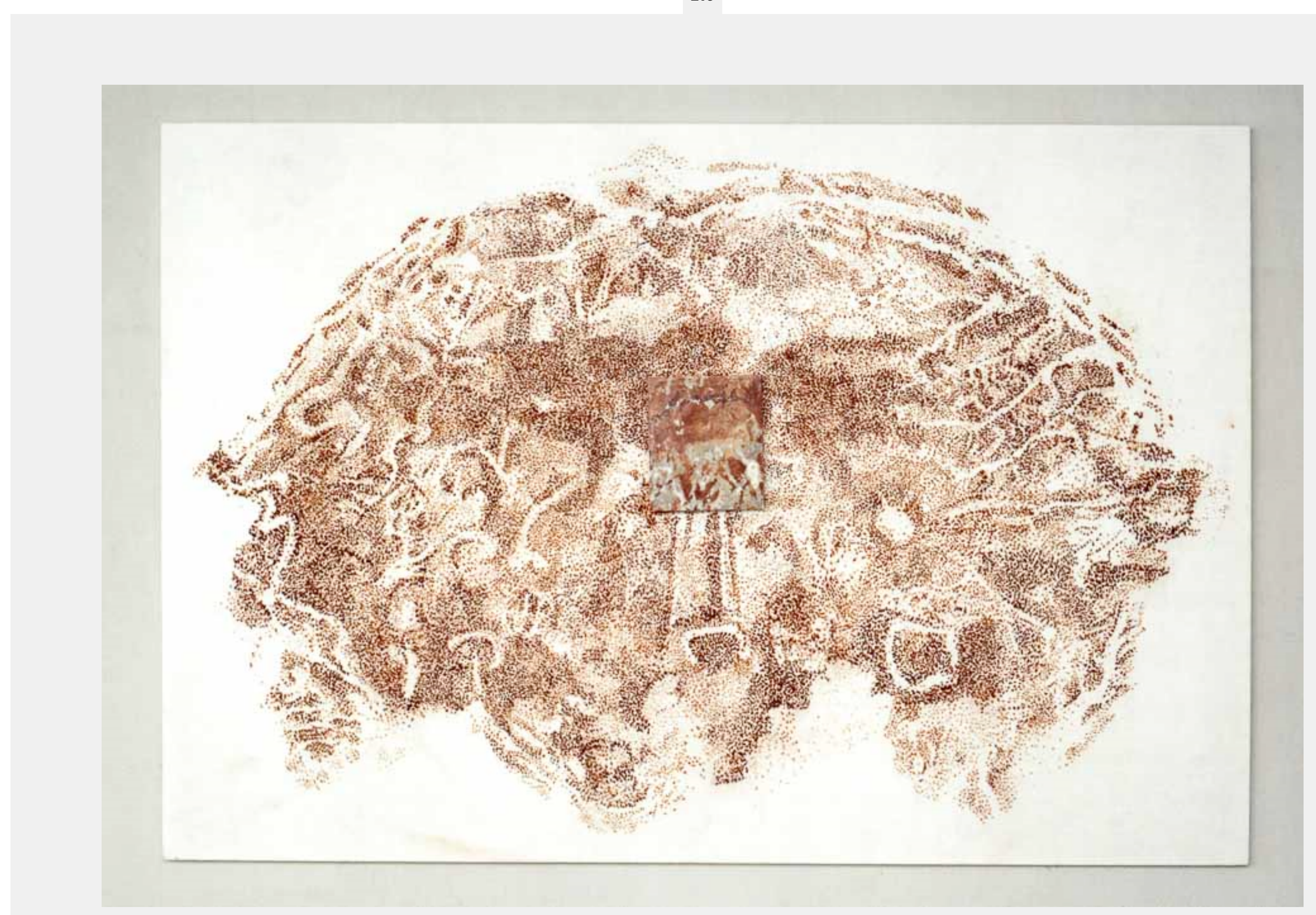

Paesaggio del cervello, 1997 Foto (c) Arquivo Penone 
1. la volontà di un rapporto paritario tra la mia persona e le cose. PENONE apud BAILLY, 2008, $\mathrm{p}$ 64. TN

2. Giuseppe Penone. Scritti 1968 - 2008. Bologna: MAMbo - Istituzione Galleria d'Arte
Giuseppe Penone vive e trabalha em Turim, onde realizou suas primeiras mostras a partir de 1968, juntamente com outros componentes do grupo Arte Povera. Desde então, o que o move é a "vontade de uma relação paritária entre a [sua] pessoa e as coisas"1 e toda a sua produção é conduzida pela noção de que homem e natureza são indistintos. Penone explora a cultura inerente à natureza, em absoluto detrimento das categorias criadas pelo homem para, por exemplo, dividir os animais, vegetais e minerais em reinos. De tal forma emerge, tanto na plástica de suas esculturas quanto em seus desenhos, a imbricação recíproca que existe entre os seres e os elementos que compõem o cosmo.

Talvez possamos afirmar que todos os trabalhos do artista trazem a poética do devir-outro: seja o devir-outro de si no tempo, como, por exemplo, em sua obra Cedro di Versailles, 2000-03, ou devir a forma e a imagem de outra matéria, como nos trabalhos aqui apresentados, Foglia e Paesaggio del cervello, ambos realizados a partir de 1990.

O conjunto da obra de Giuseppe Penone abrange, além de esculturas, desenhos e ações performáticas, também a produção de textos, que foram compilados na edição Scritt 1968-2008 ${ }^{2}$. Cada escrito seu poderia ser pensado como um pensamento-gravura, ou seja, uma gravação, uma inscrição ou a materialização de seus pensamentos:
Ocorre-me escrever algo porque a obra nasce sempre de uma reflexão. A minha é, portanto, uma nota que endereça a leitura. Às vezes procuro escrever as razões pelas quais realizo um trabalho, não com a intenção de fornecer uma explicação, mas criando uma associação de ideias e de imagens que dão origem a elementos para meditar, desenvolver e sintonizar o próprio trabalho $[. .$.

A palavra é usada por mim como parte de uma reflexão que acaba assumindo um valor diferente e autônomo. Nasce próxima da obra, às vezes sobre um trabalho já realizado, às vezes que o precede em muitos anos. [... $]^{3}$

$\mathrm{O}$ ato de transmutar, que faz com que o pensamento se corporifique em seus escritos, esse devir-texto do pensamento, tem lugar também, de certa forma, tanto em Foglia quanto em Paesaggio del cervello, em concordância com a reflexão do artista, escrita em 1989:

A caixa craniana adapta-se à forma que protege.

O osso do crânio é matéria plástica para o cérebro que o constitui, adapta-o à sua forma. O cérebro adere ao crânio sobre o qual registra as suas pulsões, mas não é capaz de ler a superfície que toca.

Para compreender e ter consciência da forma da superfície interna

do crânio, é preciso tocá-la com as mãos, vê-la com os olhos.
3. Mi capita di scrivere qualcosa perché lopera nasce sempre da una riflessione. [...] A volte cerco di scrivere le ragioni per le quali realizzo un lavoro, non con intenzione di fornire elementi per meditare sviluppare e mettere. meglio a punto il lavoro stesso. meglio a punto il lavoro stesso. p. 331.
EM TESE
BELO HORIZONTE
v. 21
N. 3
SET.-DEZ. 2015
PENONE. Foglia e Paesaggio del cervello
P. 208-218 
4. La scatola cranica si adatta alla forma che protegge. L'osso del cranio è materia plastica per il cervello che costituisce,

lo adatta alla sua forma. II

cervello aderisce al cranio, su

quale registra

e sue puloni ma non è in grado

di leggere la superficie che tocca.

Per capire ed avere coscienza

della forma della superficie

interna

del cranio occorre toccarla con

mani, vedocon

Ė un vero paesagi occhi.

avvallamenti, etti di fium

montagne, pianori,

un rilievo simile alla crosta

terrestre.

Il paesaggio che ci circonda lo

possediamo all'interno

di questa scatola di protezione. È

del qua pensiomo

del quale pensiamo. Ë

PESTIE, 2009, TN.
É uma verdadeira paisagem, com depressões, leitos de rios, montanhas, planícies, um relevo similar à crosta terrestre.

A paisagem que nos circunda, a possuímos dentro

desta caixa de proteção. É a paisagem dentro

da qual pensamos. É a paisagem que nos envolve.

Uma paisagem a ser percorrida, sentida, conhecida com o tato,

a ser desenhada ponto por ponto. ${ }^{4}$

O pensamento, um ano depois de tomar corpo neste escrito, corporifica-se nas obras Foglia e Paesaggio del cervello, que são, por sua vez, corpos outros da paisagem do mundo, como revela a disposição de um galho sobre um de seus desenhos. Estas obras exibem, como antecipava o próprio artista, que temos gravada dentro de nós, no lugar em que as imagens se formam - em nosso cérebro - a paisagem do mundo. Para mostrá-lo, ele dispôs bandagens sobre a superfície interna de um crânio, lançando mão do frottage, ou seja, esfregando sobre elas determinados tipos de pigmento, de modo a decalcar o relevo da superfície sobre a qual se esfrega. O que Penone obteve pelo frottage do crânio são, por fim, modos de devir-outro: as imagens que vemos em Foglia e em Paesaggio del cervello, além de trazerem a paisagem do mundo corporificada em nós, são também nosso devir-paisagem, nossa topografia craniana que, por sua vez, formou-se a partir de um tipo especial de frottage, o contato travado entre cérebro e crânio.

Por Marina Câmar
EM TESE
BELO HORIZONTE
v. 21
N. 3
SET.-DEZ. 2015
PENONE. Foglia e Paesaggio del cervello 